Acta horticulturae et regiotecturae 2

Nitra, Slovaca Universitas Agriculturae Nitriae, 2014, p. 35-37

\title{
LANDSCAPE AS A RESOURCE FOR SQUAT FARMING
}

\author{
Attila TÓTH*, Ĺubica FERIANCOVÁ \\ Slovak University of Agriculture in Nitra, Slovakia
}

\begin{abstract}
The contemporary Urban Agriculture (UA) is represented by a range of diverse farming typologies taking place in the urban environment. Nowadays, there is an unconventional form of UA called squat farming. The research object of this paper is represented by the case study of Can Masdeu which stands for a squatted and cultivated land at the northern city border of Barcelona. The goal of our Short Term Scientific Mission carried out in the Barcelona Metropolitan Region was to define and study diverse typologies of $\mathrm{UA}$ at different levels and scales. One of these types is represented by the ongoing phenomenon of squat farming. Concerning this form, there are two main research questions: 1) How are landscape and urban structures influenced and formed by the activity of land cultivation? and 2) How is the social dimension of squat farming structured - who are the users, what is their motivation, aim and vision? To answer the first research question, we applied spatial and perceptual analyses, and concerning the second research question, the users have been interviewed within discussions and questionnaires. The results include characteristics of spatial and social dimensions of squat farming described on the case study of Can Masdeu.
\end{abstract}

Keywords: squat farming, urban agriculture, spatial and perceptual analysis

The occurrence of squatting in Barcelona has been noticeably increasing since the last decade as a reaction on high real estate prices due to realty speculations. Cultivated squatted urban and peri-urban areas represent a significant element of Urban Agriculture (UA) which according to Lohrberg (2011) and the COST-Action UAE (2012) provides an important contribution to a sustainable and resilient urban development and the creation and maintenance of multifunctional urban landscapes. UA has been increasingly recognised for the multiple functions that it supports and that benefit urban society (Bryant, 2012). UA uses the urban and peri-urban landscape as a resource for farming activities.

The Barcelona Declaration on UA and the CAP (COSTAction UAE, 2013) defines UA as: „... spanning all actors, communities, activities, places and economies that focus on bio-based production, in a spatial context that, according to local opinions and standards, is perceived as "urban". UA takes place in intra-urban and peri-urban areas."

UA is more than growing vegetables in the city. It is about finding and implementing new ways of achieving multiple objectives through food and about the potential to make cities more liveable and sustainable (Jäggi, 2011).

\section{Material and methods}

This paper is based on the methodology and results of the $1^{\text {st }}$ Short Term Scientific Mission (STSM) of the COST-Action TD1106 Urban Agriculture Europe (UAE) in the Barcelona Metropolitan Region presented at the $2^{\text {nd }}$ WG meeting of the action in Castelldefels on the $12^{\text {th }}$ of March 2013 and reported in the STSM report (Giacchè and Tóth, 2013).

We analysed Can Masdeu as an example of the contemporary phenomenon of squat farming located on the hillside at the northern city border of Barcelona by the method of field trip and interviews.

\section{Spatial and perceptual analysis}

Our analysis focuses on 1) spatial situations (how UA appears in landscape and urban structures and how is it impacted by 3-dimensional elements like buildings, vegetation etc.); 2) uses / users and observers and 3) atmosphere (explored by observation and perception of the space. We define visual and functional linkages between UA sites and their surroundings. The perception of the analysed example of UA is based on observation, experiencing the essence of the space, its multifunctionality, and multilevel values. Within the interviews several questions have been formed in order to find out the role of UA for the actors (users of the space, stakeholders, and observers) and their perception of the space and its surroundings.

\section{Results and discussion}

The first part of the results focuses on the origin, general information and aims of the project gained by interviews and questionnaires. Can Masdeu arose more than a decade ago at the place of a former hospital which has been abandoned for 40 years and covers an area of around 1.6 hectares. A group of people started to use the space with the aim to live in a different way, a more sustainable one. They want to restore the former land use in the overgrown valley (horticulture and forestry) and to use the empty building as a place to live. Farmers living in Can Masdeu produce vegetables covering around 80 percents of their needs and organise workshops about permaculture, agro-ecology and other issues within the education about sustainability and self-sufficiency.

The second part of the results focuses on perceived attributes of the farming space according to results of the spatial and perceptual analysis. Although Can Masdeu is located very close to the city, its character is very countryside-like as it is situated on a hillside and surrounded by successive pine forests. The geomorphology and the 


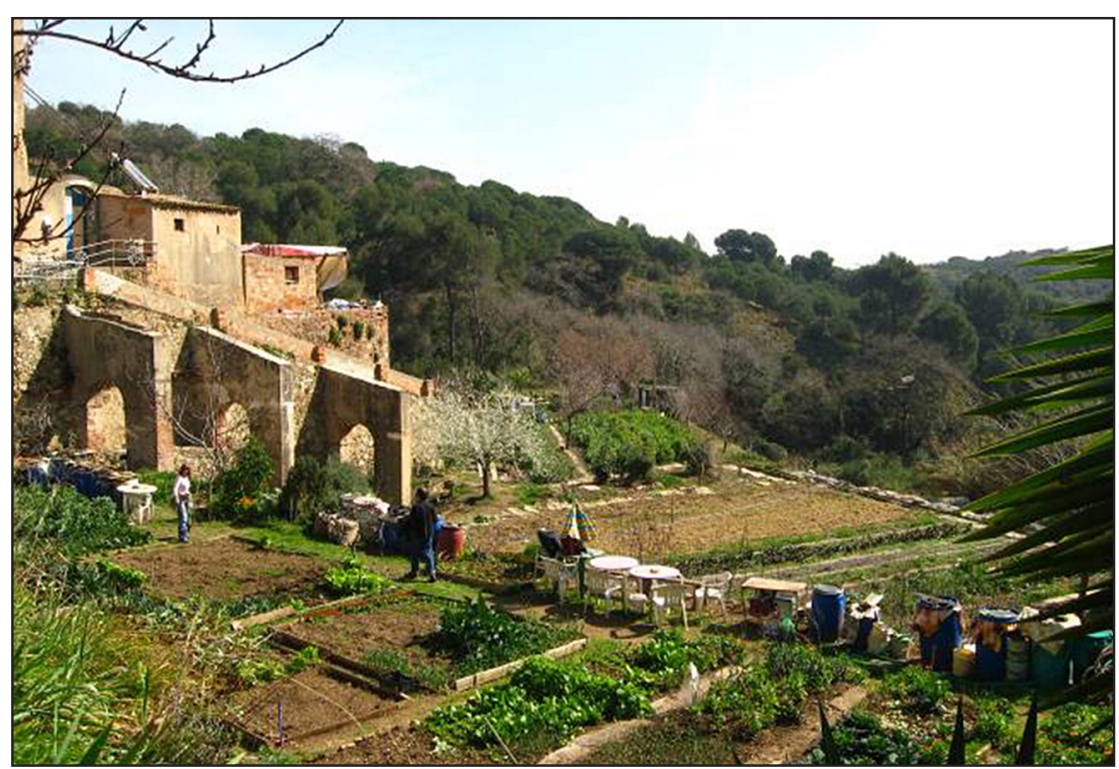

Figure 1 The overall atmosphere of the squat-farm space is significantly impacted by the structured cultivated land divided into small plots. The space is dominated by the architectural element and framed by the woodland which in terms of perception encloses the space Source: Tóth, 2013

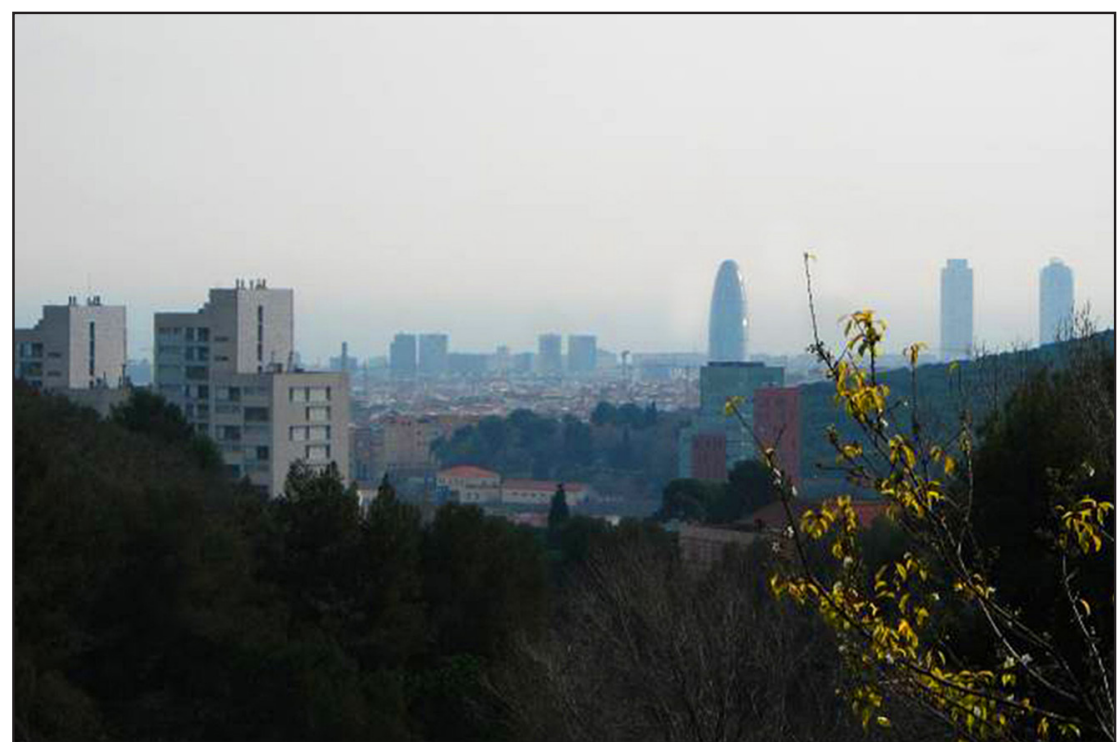

Figure 2 The view to the skyline of Barcelona from Can Masdeu represents a visual and perceptual linkage between the urban area and its boundary and underlines the urban context of the farming in Can Masdeu

Source: Tóth, 2013

vegetation cover create an atmosphere of a closed, intimate, hidden and forgotten space linked directly to the nature (see Figure 1).

Only some views to the skyscrapers of Barcelona from upper terraces of Can Masdeu remind us that we are right at the city border. They serve as a visual mental linkage (see Figure 2).

The squat-farm landscape is dynamized by the intensively cultivated perceive the space as an element reconnecting them with the nature, as a space to find an own lifestyle by using and reusing resources, waste reduction and ecological farming. They form a community linked to nature and heading towards food selfsufficiency and sustainable way of life (see Figure 4).

Research into UA seems to be a very relevant approach as according to Lorleberg (2012), it makes a critically important contribution to sustainable development and covers all components of sustainability: economy, society and environment. We deal with issues concerning space, use and perception of UA as there are according to Veen (2012) two main things which need to be changed: processes and perceptions concerning multifunctionality and values of UA. Paradis (2012) states that according to the European Landscape Convention, the role of local society concerning definition of interests and values of their landscapes should be considered and the governance should take in consideration perceptions and values of different stakeholders. Taking into account this statement, we compared our perception of UA sites with perceptions by users of the spaces. We emphasise the multifunctional use of squat farming as according to Chowney (2012), multifunctionality of a space represented by a range of functions (productivity, leisure, accessibility, environment, education, etc.) makes a landscape successful and working.

\section{Conclusion}

This paper defines and characterises an example of the contemporary phenomenon of squat farming which represents an integrated element of UA. It analyses and describes the spatial and perceptual situation and characteristics of the case study of Can Masdeu at the northern urban boundary of Barcelona city in Spain. The results of this study provide contemporary information about spatial context, perception and atmosphere of a squat farm and thereby contribute to the COST-Action TD1106 Urban Agriculture Europe. Our results represent a framework which can be applied to different cases of UA situated in diverse cultural contexts. 


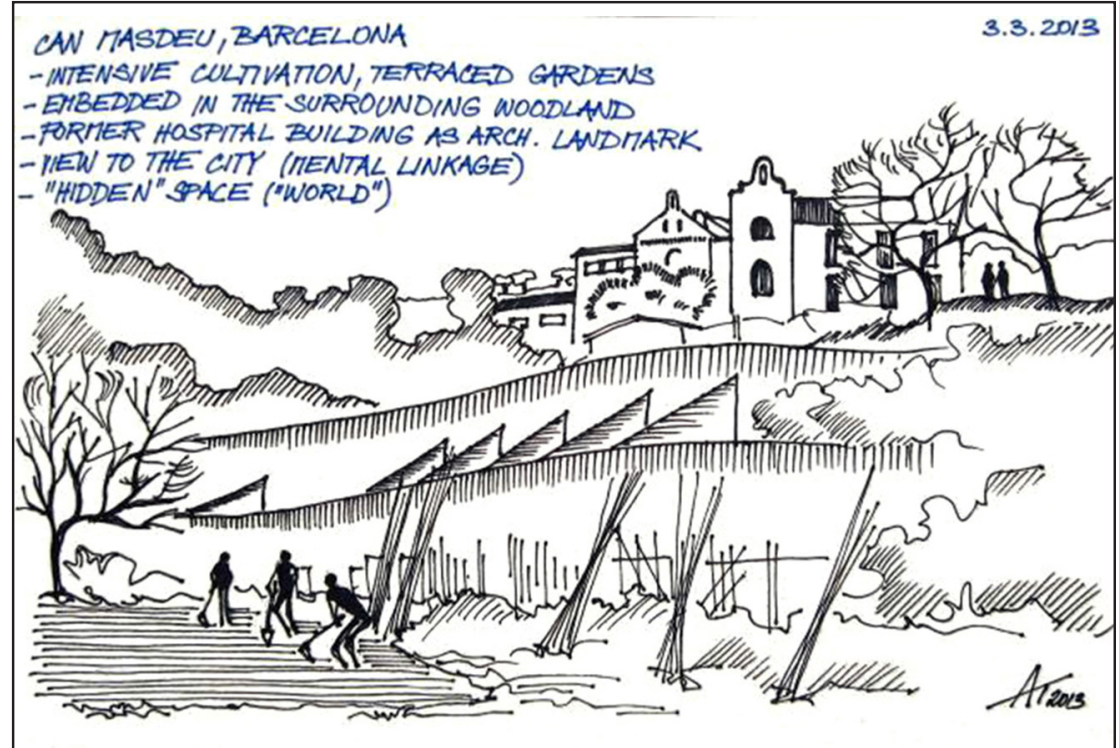

Figure 3 The local identity of the squat-farm space is represented by the terraced farmland, where the former hospital buildings stand for the dominant architectural landmarks. The farming activity is in accordance with the former land-use in the valley and the farm itself is an integrated part of the landscape

Source: Tóth, 2013

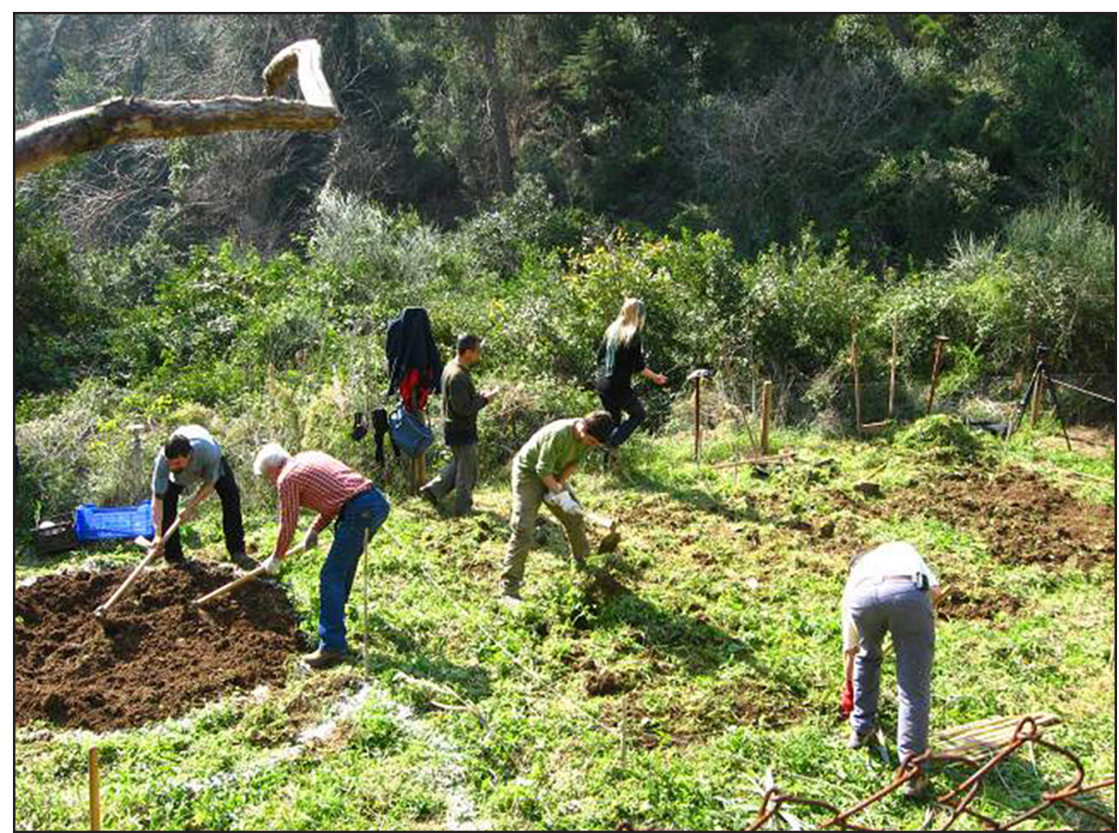

Figure 4 The social dimension of farming consists in forming a coherent community

Source: Tóth, 2013

\section{Acknowledgement}

We wish to thank the COST-Action TD1106 UAE for financial and organisational support of the STSM in Barcelona (2013) and the research projects of the Ministry of Education of the SR KEGA no. 020SPU-4/2011 and VEGA no. 1/0769/12.
CHOWNEY, Ch. 2012. How to make the landscape work? In COST Action Urban Agriculture Europe: Documentation of $1^{\text {st }}$ Working Group Meeting. Aachen : COST, ESF, RWTH Aachen University, 2012. pp. 46-47.

COST-Action UAE. 2013. Barcelona Declaration on Urban Agriculture and the Common Agricultural Policy [online] Available at: http://www. urbanagricultureeurope.la.rwth-aachen. de/mediawiki/index.php/\%22Barcelona Declaration_on_Urban_Agriculture_and the_Common_Agricultural_Policy\%22> [Accessed 16 April 2013].

COST-Action UAE. 2012. COST Action Urban Agriculture Europe [online] Available at: http://www.urbanagricultureeurope. la.rwth-aachen.de/> [Accessed 16 April 2013].

GIACCHÈ, G. - TÓTH, A. 2013. COST-Action Urban Agriculture Europe: UA in Barcelona Metropolitan Region: Short Term Scientific Mission Report [online]. Available at: http:// www.urbanagricultureeurope.la.rwthaachen.de/files/130319_stsmreport barcelona.pdf> [Accessed 16 April 2013].

JÄGGI, M. 2011. Urban agriculture as an instrument of sustainable city planning: A case study from Toronto, Canada. In Scales of Nature: $48^{\text {th }}$ IFLA World Congress Proceedings. Zürich : IFLA, BSLA, 2011. pp. 69-70.

LOHRBERG, F. 2011. Urban agriculture General aspects and examples from Germany. In Scales of Nature: $48^{\text {th }}$ IFLA World Congress Proceedings. Zürich : IFLA, BSLA, 2011. p. 148.

LORLEBERG, W. 2012. Working Group 3: Entrepreneurial models of Urban Agriculture. In COST Action Urban Agriculture Europe: Documentation of $1^{\text {st }}$ Working Group Meeting. Aachen : COST, ESF, RWTH Aachen University, 2012. pp. 29-31.

PARADIS, S. 2012. How should / can landscape be planned? In COST Action Urban Agriculture Europe: Documentation of $1^{\text {st }}$ Working Group Meeting. Aachen : COST, ESF, RWTH Aachen University, 2012. p. 45.

VEEN, E. 2012. What has to / can be changed? In COST Action Urban Agriculture Europe: Documentation of $1^{\text {st }}$ Working Group Meeting. Aachen : COST, ESF, RWTH Aachen University, 2012. pp. 44-45.

\section{Contact address:}

*Ing. Attila Tóth, Slovak University of Agriculture, Faculty of Horticulture and Landscape Engineering, Tulipánová 7, 94976 Nitra, Slovakia, phone: +421 37 64154 47, e-mail: at.attilatoth@gmail. com 